\title{
Barrier to Healthcare Access Faced by Indigenous Women in the Guatemalan Highland.
}

Emily A. Kragel

Duke University, emilykragel@gmail.com

Logan N. Beyer

Duke University, logan.n.beyer@gmail.com

David L. Boyd

DipTOM, PhD, Duke Global Health Institute, david.boyd@duke.edu

Follow the International Journal of Indigenous Health at:

https://jps.library.utoronto.ca/index.php/ijih/index

Recommended Citation:

Kragel, E. A., Beyer, L. N., \& Boyd, D. L. (2018). Barrier to Healthcare Access Faced by Indigenous Women in the Guatemalan Highland. IJIH, 13(1), 104 -121. DOI:10.32799/ijih.v13i1.30303 


\title{
Barrier to Healthcare Access Faced by Indigenous Women in the Guatemalan Highland.
}

\begin{abstract}
Utilizing the Framework Method, qualitative research determined the effects of potential barriers to healthcare access faced by 15 self-selected, consenting Indigenous women living in three different communities in the Guatemalan highlands. The women were actively involved in the nutritional recuperation program of the Community Organization, a non-profit clinic. Data collection involved recorded interviews based on a questionnaire designed to ensure culture competency. Responses were grouped into categories based on their relation to potential barriers to healthcare access and were then coded based on impacts on healthcare seeking behaviours. Intercoder reliability was measured and negotiated agreement of results was conducted to reach 100\% agreement. Analyses of coded responses compared results between communities and between available sectors of healthcare (folk, public, and non-profit). Inductive reasoning was used to determine the effect of beliefs related to illness on healthcare seeking behaviour. Analyses showed significant differences in the impact of geographical barriers to healthcare access among communities across public and non-profit sectors of healthcare, $p<$ 0.05 , and demonstrated categorization of disease states and influence of beliefs related to illness on healthcare seeking behaviour. Results demonstrated a hierarchy of barriers, with barriers such as cost, perceived quality of care, trust of medical provider, and available time only showing a negative effect once the barrier of geography was overcome. Despite the sample bias, these results give insight into factors affecting healthcare seeking behaviours that could contribute to the low utilization of healthcare seen in this population.
\end{abstract}

\section{Keywords}

Healthcare Access, Indigenous Health, Maya, Qualitative Analysis, Cultural Beliefs.

\section{Creative Commons Licence (c) 109}

This work is licensed under a Creative Commons Attribution-Noncommercial-No Derivative Works 4.0 License. 


\section{Glossary}

Mal de ojo: Evil eye, illness affecting children when someone looks at them with a strong glance, causing an imbalance in their normal state of heat that is attributed to be the cause of a variety of symptoms including vomiting, diarrhea, crying, lack of appetite, lack of sleeping, fever, intestinal infection, and susto (fright). Natural remedies that can cure mal de ojo involve the use of rue, peppers, oil, passing an egg over the body, alcohol, or garlic.

Lombrices: Worms that are believed to exist in the stomach since birth. A variety of digestive disorders are attributed to the activation of these worms.

Chipe: Illness that occurs when a child becomes jealous or emotional when their mother is pregnant. Symptoms include crying and loss of appetite

\section{Introduction}

Compared with other countries in Latin America, Guatemala is among the most populated and the poorest (Bowser \& Mahal, 2011). Guatemala experiences major health challenges, including high rates of malnutrition, infant mortality, and maternal mortality (World Health Organization, 2017). General trends in epidemiology in Guatemala include high incidence of infectious disease, malnutrition, malaria; increasing rates of infectious disease, malnutrition, AIDS, cardiovascular disease; and decreasing rates of pulmonary tuberculosis and communicable disease mortality (Gragnolati \& Marini, 2003; Pan American Health Organization, 2007). Worsened health outcomes are seen in both rural and Indigenous populations. Infant mortality rates are higher in Guatemala than other countries in Latin America, with even higher rates among Indigenous populations in the highlands (Lang \& Elkin, 1997). Rates of maternal mortality and chronic malnutrition are also higher among the Indigenous population in Guatemala (World Health Organization, 2017). The Indigenous people make up $41 \%$ of the total population in Guatemala, with $76 \%$ of the Indigenous population described as poor and $29 \%$ as extremely poor (Pan American Health Organization, 2007). Mayan residents of the rural highlands experience limited access to healthcare services with few available providers (Bhatt, 2012). Additionally, life expectancy at birth is three years lower for Mayan women compared to that of the general population of Guatemala (Schooley, Mundt, Wagner, Fullerton, \& O'Donnell, 2009). It is evident that the health challenges faced by Guatemalans affect the Mayan population to a much greater extent.

The pluralist medical system in Guatemala provides a disjointed platform for confronting these poor health outcomes. The public sector, under supervision of the Guatemalan Ministerio de Salud Pública y Asistencia Social (Ministry of Health and Social Welfare) provides public health posts and health centers that are not commonly accessible for the Mayan population. The health posts that are accessible to the Indigenous population typically offer limited services and are under-staffed (Bhatt, 2012). The private sector is separated into non-profit and for-profit divisions. For-profit hospitals are located near cities and are expensive; non-profit clinics are not common and experience a shortage of resources due to the nature of being non-profit. Lastly, the folk sector includes traditional healers and lay people and are classified as curers, midwives, massage specialists, and spiritual healers (Bhatt, 2012). Midwives typically learn basic 
skills from older relatives and do not receive formal training (Cooper \& Yarbrough, 2010). Despite the variety of facilities, utilization of healthcare services is low (Annis, 1981; Bhatt, 2012). It is estimated that over $40 \%$ of the population does not have access to affordable adequate healthcare services, an issue common in Spanish speaking countries around the world (Nations, 2012). One potential reason for the poor health outcomes in Guatemalan Indigenous populations could be a lack of access to healthcare. The identification and quantification of barriers to healthcare access can help identify social determinants of health affecting the Indigenous communities in Guatemala.

\section{Potential Barriers}

Geography. One potential barrier is the physical distance separating these communities from healthcare. It has been documented that hospitals are typically located farther away from Mayan communities, leaving only traditional healers and lay people accessible to rural populations (Bhatt, 2012; Lang \& Elkin, 1997). One study showed that people living more than 3.5 kilometers from a health post only accounted for $15 \%$ of those who visit the health post (Bhatt, 2012). Geography plays a role in limiting healthcare seeking behaviours, but since the majority of the Mayan highland population lives within five kilometers of a public health post it is apparent that other factors limit healthcare access (Annis, 1981).

Lack of available time. Lack of available time could deter individuals from healthcare seeking behaviours. This category of healthcare barrier considers the time it takes to travel to and wait at a medical center before receiving attention. The implications of which include not being able to work, care for children, or take care of the household (Grimes, Bowman, Dodgion, \& Lavy, 2011; Lang \& Elkin, 1997). Thus, available time is a reasonable deterrent to healthcare seeking behaviours across healthcare facilities.

Trust in medical providers. With respect to Indigenous populations, the trust in medical providers could limit healthcare access. These populations have experienced a history of oppression by the Ladino (mestizo) population that predominately makes up the professional and private healthcare sector (Bhatt, 2012; Quintana \& Segura-Herrera, 2003). As described in a report prepared by the Pan American Health Organization, there exists a lack of cultural sensitivity in the practice of modern health workers (Hughes, 2004). These modern practices do not consider the holistic view of health held by many Indigenous people; this holistic view requires a balance of the mind, body, and spirit (Hughes, 2004). This history and perceived misunderstanding of cultural beliefs contribute to the mistrust that exists between Indigenous populations and healthcare professionals. Schooley et al. (2009) confirms the influence of trust in medical providers as researchers describe a woman's decision to seek healthcare as determined by whether or not this care is perceived as safe, secure, and culturally appropriate (Schooley et al., 2009).

Perceived quality of care. It has been documented that poorly perceived quality of care is a deterrent of healthcare seeking behaviours. This issue is a common barrier to seeking obstetric care (Berry, 2008). It is important to note that the patient determines the quality of care, a practice that is different than in Western care standards. For this reason, differences in beliefs relating to illness and treatment could 
contribute to perceived quality of care. The lack of medical equipment, trained staff, and medication also negatively influences the perceived quality of care in public health posts (Bhatt, 2012; Grimes et al., 2011). Thus it has been proposed that poorly perceived quality of care prevents healthcare seeking behaviours, particularly with respect to public health services.

Cost. As stated, $76 \%$ of the Indigenous population is described as poor, and $29 \%$ as extremely poor (Pan American Health Organization, 2007). As a result, cost of medical treatment is likely a large barrier to healthcare access. The small fee per visit at the government health posts is relatively high compared to family incomes (Bhatt, 2012). A larger issue associated with cost is not the provider fees but the high cost of medication (Bhatt, 2012). Other associated costs include the cost of transportation and loss of income (Grimes et al., 2011). Bhatt describes the care from traditional healers and public health posts as the only economically feasible healthcare options for the Maya (Bhatt, 2012). This evidence supports that cost is a deterring factor to healthcare access.

Machismo. The power imbalance between genders is widespread throughout the Mayan population (Bellino, 2009). This dynamic, characterized as machismo, often leads to verbal and physical abuse (Suarez \& Jordan, 2007). It also acts as a barrier to healthcare access for women and children, since this imbalance grants males dominant authority over household decisions, including the spending of money on healthcare services (Carter, 2004; Schooley et al., 2009). As described by Hughes, the ability of a woman to reach a state of good health and quality of life is dependent on their relationship with men and the established gender roles (Hughes, 2004). Therefore, machismo could have act as a barrier to healthcare access for many Indigenous families.

Cultural Beliefs. Cultural beliefs relating to illness could deter healthcare seeking behaviours. Illness, as perceived by traditional Mayan beliefs, is a result of an imbalance of hot and cold in the body caused by a variety of factors (Hawkins, 2007; Messer, 1987). Traditional remedies to restore balance within the body include herbal cures, certain foods, or sweat baths (Bhatt, 2012). Although it has been stated that the use of traditional healers using these remedies is declining, the preference of these remedies influences healthcare seeking behaviours (Bhatt, 2012; Grimes et al., 2011). Thus, cultural beliefs relating to illness is another potential barrier to healthcare access.

\section{Study Location}

\section{Methods}

Research was conducted in three communities within the area the Community Organization serves.

\section{Population}

Five women from each community (Table 1), Community 1, Community 2, and Community 3, were self-identified. The purpose of this research was explained to each participant to help support clinic 
development and improvement of programming and service delivery. Informed consent to participate prior to beginning the interview was provided verbally by each participant, with use of an approved oral consent script that detailed research proceedings. The participants volunteered for participation during Nutritional Recuperation Program meetings. All women involved in this program are Indigenous and Spanish speaking.

\section{Table 1}

Characteristics of Women Interviewed, Average of 25.1 Years with 2.7 Children.

\begin{tabular}{|c|c|c|c|c|c|}
\hline Community & Age & $\begin{array}{l}\text { Marital } \\
\text { Status }\end{array}$ & Occupation & $\begin{array}{c}\text { Number of } \\
\text { Living } \\
\text { Children }\end{array}$ & Place of Childbirth \\
\hline 1 & 24 & Not married & Homemaker & 1 & Hospital \\
\hline 1 & 24 & Not married & Homemaker & 3 & Hospital \\
\hline 1 & 32 & Not married & Homemaker & 3 & Hospital \\
\hline 1 & 23 & Married & Homemaker & 2 & Hospital \\
\hline 1 & 19 & Married & Homemaker & 1 & Hospital \\
\hline 2 & 19 & Married & Homemaker & 1 & Hospital \\
\hline 2 & 27 & Married & Homemaker & 1 & Hospital \\
\hline 2 & 45 & Married & Homemaker & 8 & Temazcal \\
\hline 2 & 25 & Married & Homemaker & 5 & Hospital (4), midwife (1) \\
\hline 2 & 27 & Not married & Homemaker & 1 & Hospital \\
\hline 3 & 24 & Married & Homemaker & 3 & Hospital \\
\hline 3 & 24 & Married & Homemaker & 4 & Midwife \\
\hline 3 & 20 & Married & Sells flowers & 2 & Hospital \\
\hline 3 & 24 & Married & Homemaker & 2 & Midwife \\
\hline 3 & 20 & Married & Homemaker & 2 & Hospital \\
\hline
\end{tabular}

\section{Questionnaire Design}

A review of the literature informed potential barriers later discussed in the interviews. Preliminary questions were created based on this research and were written to assess the effects of potential barriers in the different sectors of healthcare that exist in this region: the public sector, the non-profit sector, and the folk sector. These questions were translated to Spanish and edited with the help of clinic leaders to ensure cultural competency (see Appendix A).

\section{Data Collection}

The interviews were conducted in Spanish, recorded using a Zoom H4 Handy Recorder, and later transcribed and translated with the help of local community members to ensure that all recorded and transcribed responses were accurately documented. 


\section{Data Analysis}

Qualitative data was analyzed based on the Framework Method previously established in the global health field (Gale, Heath, Cameron, Rashid, \& Redwood, 2013). The identified potential barriers functioned as categories, with participant responses coded based on the degree to which an identified barrier worked for or against health-seeking behaviours.

The responses were coded on a numerical scale of -2 to +2 based on whether or not the response represented a quality that would greatly prevent $(-2)$ or promote $(+2)$ seeking medical attention. The responses were analyzed for each community, in each sector of available healthcare. Two scorers analyzed data independently, and results were tested for intercoder reliability using appropriately established methods (Campbell, Quincy, Osserman, \& Pedersen, 2013). One-way ANOVA was utilized to compare variation between communities. Inductive methods were used to identify categorization of disease states based on responses to questions concerning beliefs relating to illness.

\section{Relationship}

This research was conducted in coordination with University and the Community. Institutional protocols of University were followed, with the study design being approved by the Institutional Review Board at University, protocol number D0053. The Community Organization provides support to malnourished children and pregnant women by means of medical interventions and health education. This organization allowed access to the Indigenous communities.

\section{Results}

Initial analyses achieved 58\% intercoder reliability, and negotiated agreement raised this to $100 \%$. With respect to the categories of machismo and beliefs regarding illness, it became apparent that these factors influencing healthcare-seeking behaviours could not be analyzed according to this coding scheme, as they did not appropriately fit into categories. Machismo was not reported by the sample, and thus could not be assessed. Inductive reasoning was used to determine the effect of beliefs relating to illness. The numbers of scored responses for the effect of each of the remaining potential barrier to healthcare access per sector of healthcare, as well as guidelines for coding are summarized in Appendix B and C, respectively. The averages of all responses for each community are summarized in Table 2 and Figure 1. The averages of responses in each sector of healthcare, public, non-profit, and folk, are summarized Figures 2, 3, and 4 respectively. Within the public sector, the most negative barriers (i.e., those that impeded healthcare-seeking behaviours the most) were geography, cost, and available time. Within the non-profit sector, the most negative barriers were geography and available time. Lastly, within the folk sector, the only very negative barrier to healthcare access was found to be available time. Significant differences in the community average effects of geography and cost between sectors of healthcare were found, $p<0.001$. Significant differences in the effect of geography between communities were demonstrated in the average responses for the public and non-profit sectors, $p<0.01$. 
Table 2.

Average Responses for Each Community per Category of Potential Barrier.

\begin{tabular}{lccccc}
\hline & $\begin{array}{c}\text { Geograph } \\
\mathbf{y}\end{array}$ & $\begin{array}{c}\text { Available } \\
\text { time }\end{array}$ & $\begin{array}{c}\text { Trust of } \\
\text { provider }\end{array}$ & $\begin{array}{c}\text { Perceived quality } \\
\text { of care }\end{array}$ & Cost \\
\hline Public Sector & & & & & \\
Community 1 & -1.20 & -0.80 & 0.60 & 1.20 & -1.00 \\
Community 2 & -1.25 & -0.60 & 0.60 & 0.60 & -1.00 \\
Community 3 & -2.00 & -0.20 & 0.80 & 0.80 & 0 \\
Average & -1.48 & -0.53 & 0.67 & 0.87 & -0.67 \\
\hline Non-Profit Sector & & & & & \\
Community 1 & 1.00 & -0.80 & 1.00 & 1.20 & 1.40 \\
Community 2 & -1.00 & -0.60 & 1.00 & 1.00 & 0.60 \\
Community 3 & -2.00 & -0.20 & 1.00 & 1.00 & 1.00 \\
Average & -0.67 & -0.53 & 1.00 & 1.07 & 1.00 \\
\hline Folk Sector & & & & & \\
Community 1 & 1.00 & -0.80 & 0.60 & 0.06 & 0.40 \\
Community 2 & 0.60 & -0.60 & 1.00 & 1.00 & -0.40 \\
Community 3 & 2.00 & 0.20 & 1.00 & 1.00 & -0.60 \\
Average & 1.20 & -0.53 & 0.87 & 0.87 & -0.20 \\
\hline
\end{tabular}

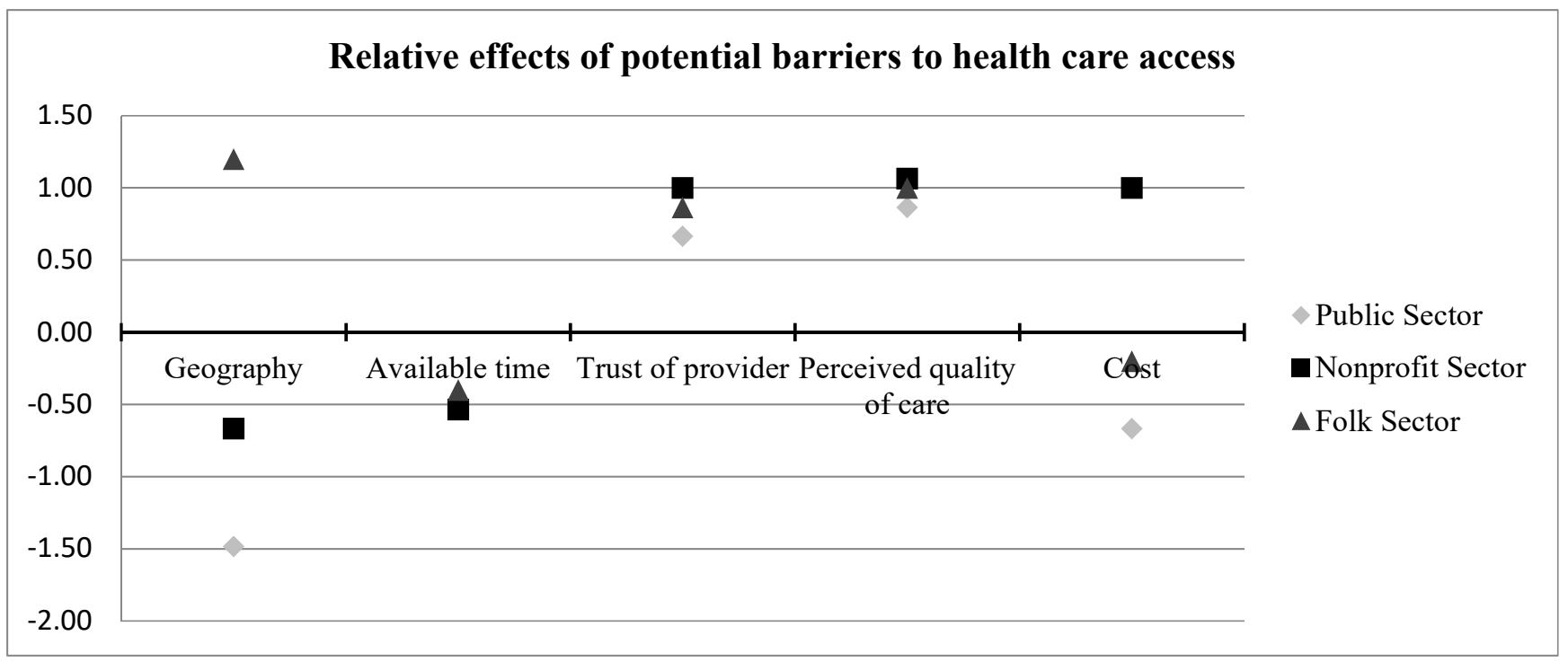

Figure 1. Graph showing the relative effects (rated by the scale shown on the Y axis) of the barriers to healthcare access that were assessed in each of the three sectors of healthcare available in the Community. Responses were averaged across the three communities that were studied. Significant differences in the community average effects of geography and cost between sectors of healthcare were found, $p<0.001$. 


\section{Beliefs Related to Illness and Categorization of Disease States}

With regards to the beliefs relating to illness, findings showed illness as belonging to one of three disease states: those that can be treated by the folk sector with natural remedies; more serious states that require attention by trained personnel outside of the folk sector; and chronic illnesses. These beliefs related to illness seemingly had a great affect on the healthcare seeking decisions.

Illnesses that could only be treated by the folk sector include mal de ojo, lombrices, and chipe. These were three illnesses that were identified as only being able to be cured by the folk sector of healthcare. More serious illnesses were recognized as needing treatment by the non-profit or public sector of healthcare. These included any illness that was not initially cured using the folk sector, childbirth when perceived to be dangerous or problematic, respiratory or cardiovascular problems, and malnutrition. Lastly, it was believed that some chronic illnesses could not cured by any sector of healthcare. These chronic issues included diabetes, ulcers, and cancer. It was unclear from the results whether or not it was thought impossible to treat and alleviate the symptoms of these illnesses, or impossible to cure them. Nevertheless, these chronic illnesses were perceived as limitations of all three sectors of healthcare.

\section{Limitations}

It is likely that other barriers negatively impact this population but were not represented in this study due to bias from the sample population. The sample of women interviewed was from a group of women participating in health programs of the Community Organization. For this reason, it is likely that machismo, trust of medical provider, and perceived quality of care may also contribute as barriers that limit access to adequate medical care, but this was unable to be demonstrated in this select sample population. Language barriers were not addressed in this study, as the population of the Community widely speaks and understands Spanish. However, approximately $40 \%$ of the population in Guatemala speaks one or more of the 23 recognized Amerindian languages (Central Intelligence Agency, 2017). Of those who speak an Amerindian language, Spanish is sometimes learned as a second language, but the dialects remain very different (A Glei \& Goldman, 2000; Beckett \& Pebley, 2003). Therefore, language barriers may also be a large problem associated with rural healthcare access in Guatemala.

\section{Comparison of Communities}

\section{Discussion}

It is important to consider the varying impacts of these barriers on the different communities. Within the public sector of healthcare, there were slight deviations between the three communities for each potential barrier to healthcare access (Figure 2). Geography was a significantly larger negative barrier to healthcare access for Community $3(p<.05)$. Cost, which was found to have a negative effect in all three communities, was found to negatively impact Community 2 the most. On the other hand, Community 3 was impacted the least out of the three communities by cost.

Community differences were also identified within the non-profit sector (Figure 3). The effect of geography was widely varied among communities. Geography had significantly larger negative impact 
in Community 3, a lesser, negative impact in Community 2, and a positive impact in Community 1 ( $p<$ $.05)$. Cost promoted health-seeking behaviours in the non-profit sector but had less of a positive effect in Community 2 and a slightly more positive effect in Community 3.

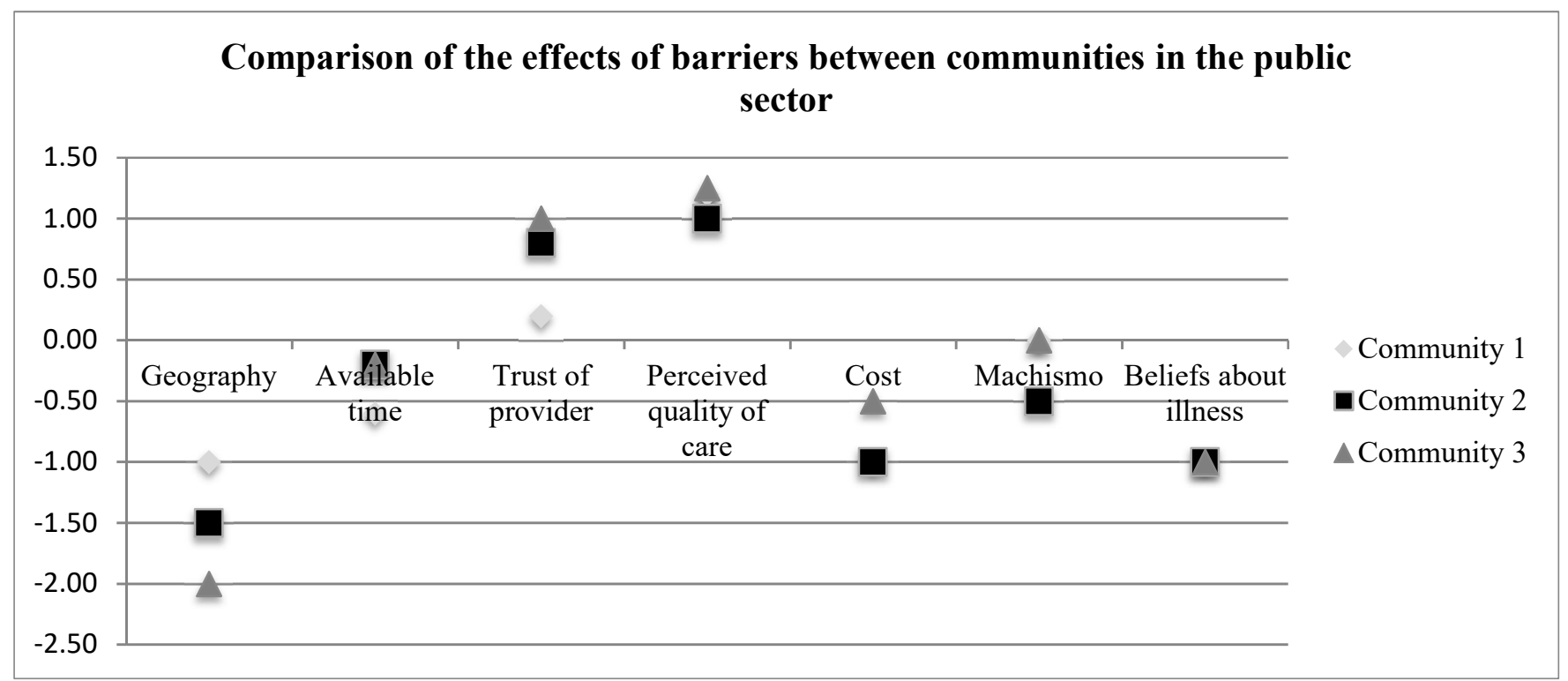

Figure 2. Graph showing the relative effects (rated by the scale shown on the Y axis) of the barriers to healthcare access in the public sector of the healthcare system as assessed in each community and averaged across the three communities. Geography was a significantly larger negative barrier to healthcare access for Community $3(p<.05)$.

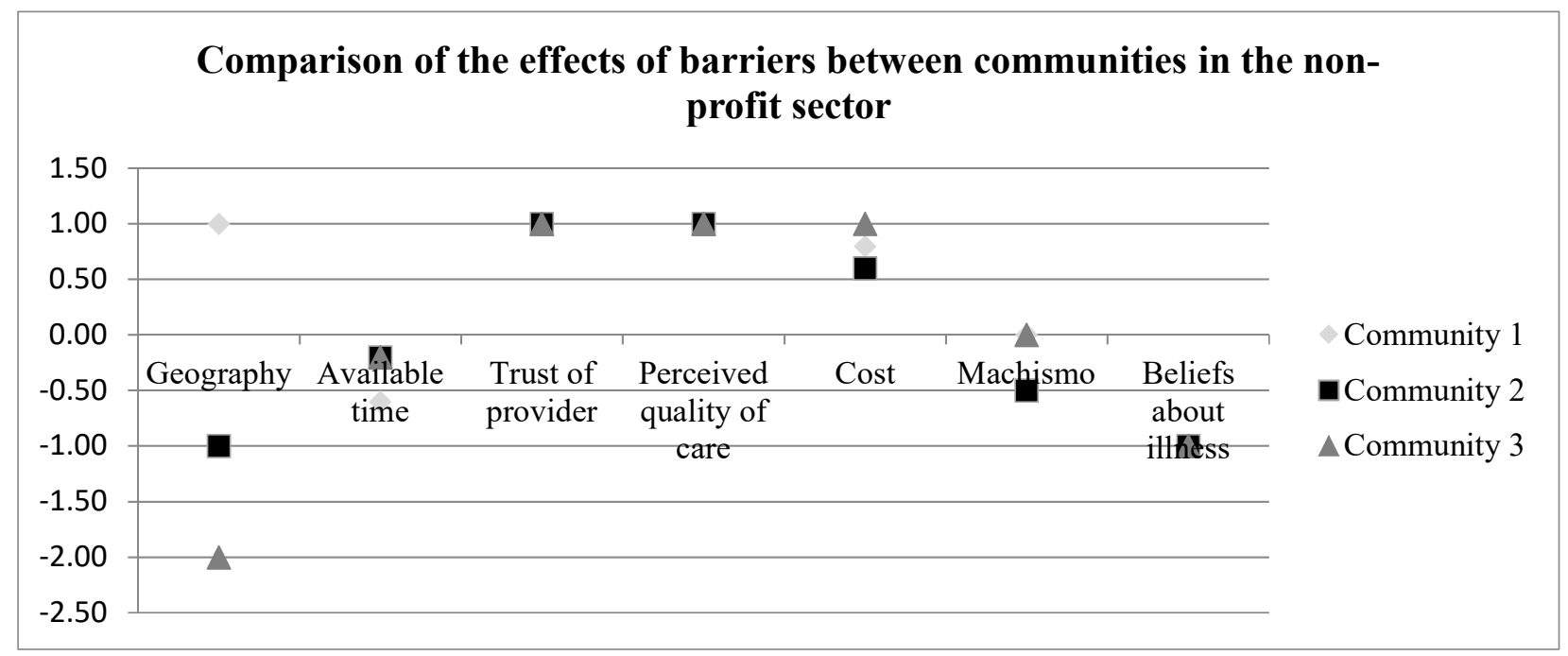

Figure 3. Graph showing the relative effects (rated by the scale shown on the Y axis) of the potential barriers to healthcare access in the non-profit sector of the healthcare system as assessed in each 
community. Geography had significantly larger negative impact in Community 3 , a lesser, negative impact in Community 2, and a positive impact in Community $1(p<.05)$.

Variance in the relative effects of the identified potential barriers was also found within the folk sector of healthcare (Figure 4). With regards to geography, this promoted healthcare seeking behaviours in all three communities and had the slightly greater positive effect in Community 3 . Available time affected each community differently. It had a slightly positive effect in Community 3 , a slightly negative effect in Community 2, and a slightly more negative effect in Community 1 . The effect of cost varied between the three communities. Cost of the folk sector hampered health seeking behaviours in Community 3 , had no effect in Community 2, and promoted these behaviours in Community 1.

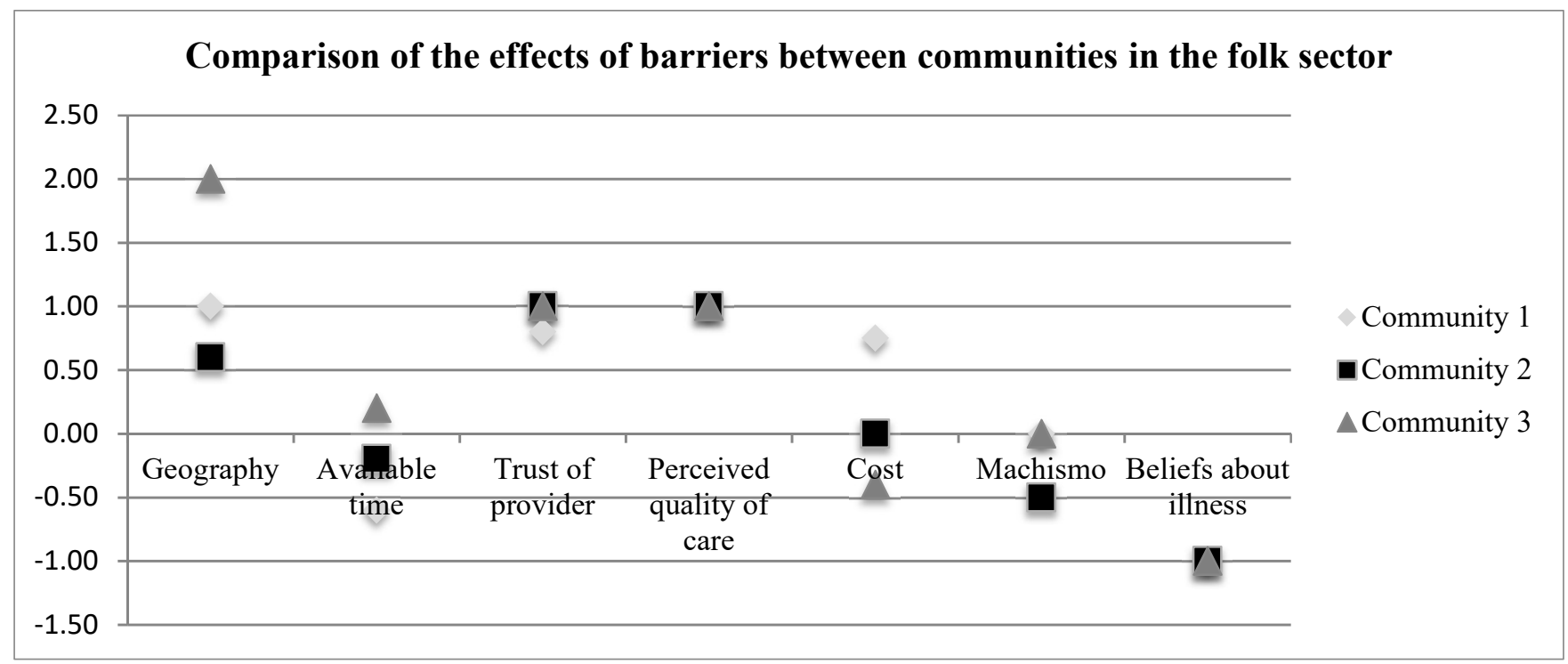

Figure 4. Graph showing the relative effects (rated by the scale shown on the $\mathrm{Y}$ axis) of the potential barriers to healthcare access in the folk sector of the healthcare system as assessed in each community. No significant differences between communities were found in the folk sector.

The differences in relative effects of barriers to healthcare access are important to note as it shows the need for individual community assessments. Analysis of these differences sheds light on a hierarchy of barriers that exist within the communities. For example, in Community 3 it is clear that the largest and most prominent barrier to the public and non-profit sectors of healthcare is geography. In the communities of Community 1 and Community 2, we begin to see the negative effect of barriers such as cost of the public sector. It is likely that cost only becomes a barrier to healthcare access once the barrier of geography is overcome. It could be important to identify the hierarchy of barriers in order to target interventions to address the most important barriers and maximize effectiveness. 


\section{Conclusion}

Ultimately it seems as though the folk sector is the most widely used among the communities. This could be due to the close proximity of community healers and midwives or to the beliefs that many illnesses can only be treated by this sector. This exemplifies the importance of culturally competent care as well as community involvement in medical education, training, and practice. This could involve working with healers and midwives. This sort of integration between westernized, modern medical practices and traditional, folk practices could be integral in expanding access to adequate healthcare in this region.

This preliminary report on barriers to healthcare access gives a small glimpse into some of the challenges that face the Community. Analysis of factors that influence healthcare seeking behaviour can help to explain why healthcare utilization is low in this population. In order to expand on this research, it would be beneficial to increase the sample size and interview a more diverse population. Additionally, it would be beneficial to conduct a more in-depth research study on the cultural beliefs of the community. This would allow for a better understanding of the illnesses that are perceived to only be able to be cured by the folk sector and improved cultural competency in medical practice. This method of identifying and ranking barriers to healthcare access seems to be an effective way to understand the root of health inequity and can be applied to improve healthcare interventions.

\section{References}

A Glei, D., \& Goldman, N. (2000). Understanding ethnic variation in pregnancy-related care in rural Guatemala. Ethnicity and health, 5(1), 5-22. https://doi.org/10.1080/13557850050007301

Annis, S. (1981). Physical access and utilization of health services in rural Guatemala. Social Science \& Medicine. Part D: Medical Geography, 15(4), 515-523. https://doi.org/10.1016/0160$\underline{\text { 8002(81)90046-0 }}$

Beckett, M., \& Pebley, A. R. (2003). Ethnicity, Language, and Economic Well-being in Rural Guatemala. Rural sociology, 68(3), 434-458. https://doi.org/10.1111/j.1549-0831.2003.tb00145.x

Bellino, M. (2009). Feminicide and Silence in" Postwar" Guatemala. Women's Policy Journal of Harvard, 7, 5 - 10.

Berry, N. S. (2008). Who's judging the quality of care? Indigenous Maya and the problem of "not being attended". Medical Anthropology, 27(2), 164-189. https://doi.org/10.1080/01459740802017413

Bhatt, S. (2012). Health care issues facing the Maya people of the Guatemalan Highlands: the current state of care and recommendations for improvement. Journal of Global Health Perspecitves, 1, 17. Retrieved from: http://jglobalhealth.org/article/health-care-issues-facing-the-maya-people-ofthe-guatemalan-highlands-the-current-state-of-care-and-recommendations-for-improvement-2/

Bowser, D. M., \& Mahal, A. (2011). Guatemala: the economic burden of illness and health system implications. Health Policy, 100(2), 159-166. https://doi.org/10.1016/j.healthpol.2010.11.011 
Campbell, J. L., Quincy, C., Osserman, J., \& Pedersen, O. K. (2013). Coding in-depth semistructured interviews: Problems of unitization and intercoder reliability and agreement. Sociological Methods \& Research, 42(3), 294-320. https://doi.org/10.1177/0049124113500475

Carter, M. W. (2004). Gender and community context: An analysis of husbands' household authority in rural Guatemala. Paper presented at the Sociological Forum.

Central Intelligence Agency. (2017). Guatemala. The World Factbook. Retrieved from: https://www.cia.gov/library/publications/the-world-factbook/geos/gt.html

Cooper, C. M., \& Yarbrough, S. P. (2010). Tell me-show me: Using combined focus group and photovoice methods to gain understanding of health issues in rural Guatemala. Qualitative Health Research, 20(5), 644-653. https://doi.org/10.1177/1049732310361894

Gale, N. K., Heath, G., Cameron, E., Rashid, S., \& Redwood, S. (2013). Using the framework method for the analysis of qualitative data in multi-disciplinary health research. BMC Medical Research Methodology, 13(1), 117. https://doi.org/10.1186/1471-2288-13-117

Gragnolati, M., \& Marini, A. (2003). Health and poverty in Guatemala. Policy Research Working Paper;No. 2966. World Bank, Washington, DC. Retrieved from: http://hdl.handle.net/10986/19187

Grimes, C. E., Bowman, K. G., Dodgion, C. M., \& Lavy, C. B. (2011). Systematic review of barriers to surgical care in low-income and middle-income countries. World journal of surgery, 35(5), 941950. https://doi.org/10.1007/s00268-011-1010-1

Hawkins, J. P. (2007). Health Care in Maya Guatemala: Confronting Medical Pluralism In A Developing Country. University of Oklahoma Press.

Hughes, J. (2004). Gender, Equity, and Indigenous Women's Health in the Americas. IndigenousPan American Health Organization. Retrieved from: http://www.paho.org/hq/dmdocuments/2011/gdrgender-equity-and-Indigenous-women-health-americas.pdf

Lang, J. B., \& Elkin, E. D. (1997). A study of the beliefs and birthing practices of traditional midwives in rural Guatemala. Journal of Midwifery \& Women's Health, 42(1), 25-31. https://doi.org/10.1016/S0091-2182(96)00069-9

Messer, E. (1987). The hot and cold in Mesoamerican Indigenous and Hispanicized thought. Social science \& medicine, 25(4), 339-346. https://doi.org/10.1016/S0091-2182(96)00069-9

Nations, E. O. (2012). Guatemala - Health. Retrieved from

Pan American Health Organization. (2007). Health Systems Profile Guatemala. Retrieved from: http://new.paho.org/hq/dmdocuments/2010/Health_System_Profile-Guatemala_2007.pdf

Quintana, S. M., \& Segura-Herrera, T. A. (2003). Developmental transformations of self and identity in the context of oppression. Self and Identity, 2(4), 269-285. https://doi.org/10.1080/714050248

Schooley, J., Mundt, C., Wagner, P., Fullerton, J., \& O’Donnell, M. (2009). Factors influencing health care-seeking behaviours among Mayan women in Guatemala. Midwifery, 25(4), 411-421. https://doi.org/10.1016/j.midw.2007.07.011

Suarez, J., \& Jordan, M. (2007). Three thousand and counting: A report on violence against women in Guatemala. Washington, DC: Guatemalan Human Rights Commission/USA, 2-8. Retrieved from: https://www.ghrc- 
usa.org/Programs/ForWomensRighttoLive/ThreethousandandCounting,AReportonViolenceAgains tWomeninGuatemala.pdf

World Health Organization. (2017). Guatemala: country cooperation strategy at a glance.

\section{Appendix A}

\section{Appendices}

Questionnaire Guidelines (translated into English)

The following questions were used to prompt a discussion relating to each topic outlined below:

1. Background questions:
a. How old are you?
b. Where do you live?
c. How many children do you have?
d. Are you married?
e. Do you have a job?
f. What do you do during a typical day?

2. Questions relating to the effect of geography:
a. How far away is the nearest public hospital?
b. How far away is Community Organization?
c. Is there a midwife or community healer in your community?
d. How long does it take to get to the public hospital?
e. How long does it take to get to Community Organization?
f. How long does it take to go to a community healer?

3. Questions relating to the effect of available time:
a. If you or a family member became ill, would you have time to go to seek medical attention?

b. Is the time it takes to get help at the hospital/Community Organization/with a community healer an obstacle that prevents you from seeking medical help when needed?

4. Questions relating to the effect of trust of medical provider:

a. What do you think of public hospitals?

b. Do you trust the people who work at the hospital?

c. Do you agree with the practices at the hospital?

d. What do you think of Community Organization?

e. Do you trust the people who work at Community Organization?

f. Do you agree with the practices of Community Organization?

g. What do you think of the community healer and the midwife?

h. Do you trust these people?

i. Do you agree with their practices?

5. Questions relating to the effect of perceived quality of care:

a. Do you think that hospitals provide effective medical care? 
b. If you went to the hospital when you were sick, would you get better?

c. How does the hospital help you?

d. Do you think that Community Organization provides effective medical care?

e. If you went to the Community Organization when you were sick, would you get better?

f. How does Community Organization help you?

g. Do you think that the community healers and midwives provide effective medical care?

$\mathrm{h}$. If you went to a community healer when you were sick, would you get better?

i. How does the community healer help you?

6. Questions relating to the effect of cost:

a. Are the medical services at the hospital expensive?

b. Are the medications at the hospital expensive?

c. Are the medical services at Community Organization expensive?

d. Are the medications at Community Organization expensive?

e. Are the medical services of a community healer or a midwife expensive?

f. Are the medications or remedies of the community healers or midwives expensive?

7. Questions relating to cultural beliefs surrounding health and sickness:

a. Are there some illnesses that cannot be cured in the hospital? What are these? How do you treat them? What are their symptoms?

b. Are there some illnesses that cannot be cured in Community Organization? What are these? How do you treat them? What are their symptoms?

c. Are there some illnesses that cannot be cured with a community healer? What are these? How do you treat them? What are their symptoms?

d. Are there some instances when a midwife cannot help you?

8. Questions relating to the effect of machismo:

a. Do you tell your husband when you or your child is sick?

b. Does your husband go with you to seek medical attention?

c. Does your husband ever stop you from seeking medical attention? 


\section{Appendix B}

\section{Table 3}

Number of Responses to the Effect of Geography per Community

\begin{tabular}{|c|c|c|c|}
\hline \multicolumn{4}{|c|}{ Public Sector } \\
\hline Score & Community 1 & Community 2 & Community 3 \\
\hline-2 & 1 & 1 & 5 \\
\hline-1 & 4 & 3 & \\
\hline 0 & & & \\
\hline 1 & & & \\
\hline 2 & & & \\
\hline \multicolumn{4}{|c|}{ Non-profit Sector } \\
\hline Score & Community 1 & Community 2 & Community 3 \\
\hline-2 & & & 1 \\
\hline-1 & 2 & 2 & 4 \\
\hline \multicolumn{4}{|l|}{0} \\
\hline 1 & 3 & 2 & \\
\hline 2 & 2 & & \\
\hline \multicolumn{4}{|c|}{ Folk Sector } \\
\hline Score & Community 1 & Community 2 & Community 3 \\
\hline \multicolumn{4}{|l|}{-2} \\
\hline-1 & 1 & 1 & \\
\hline \multicolumn{4}{|l|}{0} \\
\hline 1 & 2 & 1 & 4 \\
\hline 2 & 2 & 3 & 1 \\
\hline
\end{tabular}

\section{Table 4}

Number of Responses to the Effect of Available Time per Community

\begin{tabular}{|c|c|c|c|}
\hline \multicolumn{4}{|c|}{ Public Sector } \\
\hline Score & Community 1 & Community 2 & Community 3 \\
\hline \multicolumn{4}{|l|}{-2} \\
\hline-1 & 4 & 3 & 3 \\
\hline 0 & 1 & 1 & \\
\hline 1 & & 1 & 2 \\
\hline 2 & & & \\
\hline \multicolumn{4}{|c|}{ Non-profit Sector } \\
\hline Score & Community 1 & Community 2 & Community 3 \\
\hline \multicolumn{4}{|l|}{-2} \\
\hline-1 & 4 & 3 & 3 \\
\hline 0 & 1 & 1 & \\
\hline 1 & & 1 & 2 \\
\hline 2 & & & \\
\hline \multicolumn{4}{|c|}{ Folk Sector } \\
\hline Score & Community 1 & Community 2 & Community 3 \\
\hline \multicolumn{4}{|l|}{-2} \\
\hline-1 & 4 & 3 & 3 \\
\hline 0 & 1 & 1 & \\
\hline 1 & & 1 & 2 \\
\hline 2 & & & \\
\hline
\end{tabular}


Table 5

Number of Responses to the Effect of Trust of Medical Provider per Community

\begin{tabular}{|c|c|c|c|}
\hline \multicolumn{4}{|c|}{ Public Sector } \\
\hline Score & Community 1 & Community 2 & Community 3 \\
\hline-2 & & & \\
\hline-1 & 1 & 1 & \\
\hline 0 & & & 1 \\
\hline 1 & 4 & 4 & 4 \\
\hline 2 & & & \\
\hline \multicolumn{4}{|c|}{ Non-profit Sector } \\
\hline Score & Community 1 & Community 2 & Community 3 \\
\hline \multicolumn{4}{|l|}{-2} \\
\hline \multicolumn{4}{|l|}{-1} \\
\hline \multicolumn{4}{|l|}{0} \\
\hline 1 & 5 & 5 & 5 \\
\hline \multicolumn{4}{|l|}{2} \\
\hline \multicolumn{4}{|c|}{ Folk Sector } \\
\hline Score & Community 1 & Community 2 & Community 3 \\
\hline \multicolumn{4}{|l|}{-2} \\
\hline-1 & 1 & & \\
\hline \multicolumn{4}{|l|}{0} \\
\hline 1 & 4 & 5 & 5 \\
\hline 2 & & & \\
\hline
\end{tabular}

\section{Table 6}

Number of Responses to the Effect of Perceived Quality of Care per Community

\begin{tabular}{|c|c|c|c|}
\hline \multicolumn{4}{|c|}{ Public Sector } \\
\hline Score & Community 1 & Community 2 & Community 3 \\
\hline \multicolumn{4}{|l|}{-2} \\
\hline-1 & & 1 & \\
\hline 0 & & & 1 \\
\hline 1 & 4 & 4 & 4 \\
\hline 2 & 1 & & \\
\hline \multicolumn{4}{|c|}{ Non-profit Sector } \\
\hline Score & Community 1 & Community 2 & Community 3 \\
\hline \multicolumn{4}{|l|}{-2} \\
\hline \multicolumn{4}{|l|}{-1} \\
\hline \multicolumn{4}{|l|}{0} \\
\hline 1 & 4 & 5 & 5 \\
\hline 2 & 1 & & \\
\hline \multicolumn{4}{|c|}{ Folk Sector } \\
\hline Score & Community 1 & Community 2 & Community 3 \\
\hline \multicolumn{4}{|l|}{-2} \\
\hline-1 & 1 & & \\
\hline 0 & & 1 & \\
\hline 1 & 3 & 4 & 5 \\
\hline 2 & 1 & & \\
\hline
\end{tabular}


Table 7

Number of Responses to the Effect of Cost per Community

\begin{tabular}{|c|c|c|c|}
\hline \multicolumn{4}{|c|}{ Public Sector } \\
\hline Score & Community 1 & Community 2 & Community 3 \\
\hline \multicolumn{4}{|l|}{-2} \\
\hline-1 & 5 & 3 & 2 \\
\hline 0 & & 1 & 1 \\
\hline 1 & & & 2 \\
\hline 2 & & 1 & \\
\hline \multicolumn{4}{|c|}{ Non-profit Sector } \\
\hline Score & Community 1 & Community 2 & Community 3 \\
\hline \multicolumn{4}{|l|}{-2} \\
\hline-1 & & 1 & \\
\hline \multicolumn{4}{|l|}{0} \\
\hline 1 & 3 & 4 & 5 \\
\hline 2 & 2 & & \\
\hline \multicolumn{4}{|c|}{ Folk Sector } \\
\hline Score & Community 1 & Community 2 & Community 3 \\
\hline \multicolumn{4}{|l|}{-2} \\
\hline-1 & 1 & 3 & 4 \\
\hline 0 & 1 & 1 & \\
\hline 1 & 3 & 1 & 1 \\
\hline 2 & & & \\
\hline
\end{tabular}

\section{Appendix C}

\section{Table 8}

Description of Coding Based on Responses Used in Data Analysis

\begin{tabular}{|l|l|l|l|l|l|}
\hline & Geography & Free time & Trust & Perceived quality & Cost \\
\hline-2 & Over 1 hour travel time & $\begin{array}{l}\text { Great negative } \\
\text { effect }\end{array}$ & $\begin{array}{l}\text { Great limitation of } \\
\text { trust }\end{array}$ & Considered poor & Always unaffordable \\
\hline-1 & $\begin{array}{l}\text { Between } 30 \text { minutes to an } \\
\text { hour }\end{array}$ & $\begin{array}{l}\text { Some negative } \\
\text { effect }\end{array}$ & $\begin{array}{l}\text { Any doubt in trust } \\
\text { of limitations of } \\
\text { trust }\end{array}$ & $\begin{array}{l}\text { Considered to have } \\
\text { limitations or } \\
\text { weakness in some } \\
\text { way }\end{array}$ & $\begin{array}{l}\text { Cost sometimes } \\
\text { hindered ability to pay } \\
\text { or seek treatment }\end{array}$ \\
\hline 0 & $\begin{array}{l}\text { Travel time depends on } \\
\text { situation, answer was } \\
\text { unclear }\end{array}$ & No effect & Uncertainty & Average & Uncertainty \\
\hline 1 & Between 15 and 30 minutes & Positive effect & Basic trust & Considered good & Low cost or affordable \\
\hline 2 & Under 15 minutes & Great positive effect & Great trust & $\begin{array}{l}\text { Considered the best } \\
\text { or great }\end{array}$ & Free \\
\hline
\end{tabular}

